Session 2530

\title{
Engineering, But How?
}

\author{
Alan G. Gomez \\ Madison West High School / University of Wisconsin
}

\begin{abstract}
One of the most significant labor shortages the United States has is technologically oriented people. Every year our government accepts more and more people from foreign countries on work visas to place them in technology-related fields. Although we are doing more than we have in the past to give our students opportunities to become technologically literate, too often educators place students in front of computers and assume that computer literacy follows. Students need more than the computers and their programs. This article presents information about a $21^{\text {st }}$ century program created in 1996: a comprehensive engineering program at Madison West High School within blocks of the University of Wisconsin in Madison, Wisconsin.
\end{abstract}

\section{Introduction}

Courses including Principles of Engineering 1\&2, Materials Science, and Computer Aided Design, including mechanical design, 3D solid modeling and 3D animation, are the make-up of this $21^{\text {st }}$ century high school engineering program.

Students in engineering courses participate in at least fourteen different case studies. These case studies are diverse in nature in order to give the students just a taste of many different types of engineering. Engineering ethics, thermodynamics, mechanisms intersection design and the construction of supermileage prototype vehicles are just a few of the case studies.

Materials Science students learn about the characteristics and uses for materials ranging from a simple polymer casting to phase diagrams of metallic alloys that they create and cast in class. Students learn about techniques and application process associated with many different materials throughout the 68 hands-on experiments.

Computer Aided Design is an area that has given students in the program a superior design experience that allows them to visualize their dreams and communicate this to other members of the team without simply relying on sketches and the spoken word. Students now have the ability to animate any of their proposed prototypes in the environment that they are to be used. These 
animations and three-dimensional models serve as evaluation tools and presentation techniques during the design cycle of a prototype.

\section{Student success}

The following perspectives on the program are from students that have been through the program. Many have graduated from the program to enroll in engineering colleges across the nation and work in flourishing businesses.

Mike Kahan, Junior at Massachusetts Institute of Technology in Mechanical Engineering: "I'll tell you, the Supermileage project has been the thing that I have gotten the most mileage out of (no pun intended) from high school. Every time I show people pictures of the cars and tell them about the project, I get reactions like 'Man, I wish I could have worked on something like that in high school.' Coming from students and professors at MIT, and interviewers from companies like Cisco Systems, that's a pretty big compliment for West's engineering program."

Adam Stowitts, Senior at the University of Wisconsin-Stout in Industrial Technology-Mechanical Design: "This Program may have had one of the largest impacts on my life of any occurrence to date. Without it I know I wouldn't be headed in the professional direction I am today. The fun that I had, the things that I learned and the hours that I put in made me realize what I wanted to do with my career. Not only did it help me realize what it is that I wanted to do, but it also gave me a head start with my personal as well as engineering skills. It taught me leadership, teamwork and diplomacy as well as rewarded me for my efforts. From the moment I began college up to today I have felt like I have had the advantage over most everyone else coming out of high school. It is a great program and I plan to support it myself any way that I can."

Emery Sanford, Freshman at the University of California at Berkley in Mechanical Engineering. "The Principles of Engineering courses gave me a broad, interesting, and fun introduction to the field of Engineering. I entered as a junior with an interest in taking apart my dad's old typewriter and left as a senior to study mechanical engineering in California. Through hands on case studies like the super mileage vehicle, I decided whole-heartedly that I wanted to study and practice engineering at a professional level. I am able to relate what I learned in engineering at west high school to my college classes on a daily basis. Not one day goes by when I don't think of the real life projects that I worked on in our high school engineering courses as I learn theoretical engineering at the university level."

Britta Muller, freshman at the Purdue University in chemical engineering: "Every day you hear about more and more kids that have already spent a semester or even a year studying engineering in college and then realized that it wasn't for them. That's what is so amazing about our program, not only do we learn the fundamentals of engineering and problem solving, we are able to decide if engineering is for us before we get to college. I will be forever grateful for what I learned inside and outside of the classroom from Mr. Gomez and my fellow classmates." 
Jaron Berman, freshman at the University of Wisconsin, college of engineering: "West High's Engineering program really is unique, one of the few courses I took that encouraged creativity. Our case studies were relevant to modern engineering problems, and I left the program with skills that helped prepare me for engineering school as well as summer opportunities."

Brian Morgan, Sophomore at the University of Minnesota: "I've learned more in this class than in any other single course; the mixture of critical thinking, designing, building, and fundraising is unique in allowing students to accomplish a challenging goal. In two years working on the Supermileage prototype, as well as other projects, I realized I've taken a lot from the experiences, and I've found that what I've taken has helped me gain a step in both college and the technical workplace."

\section{Engineering in the classroom ${ }^{1}$}

A course at Madison West High School, Principles of Engineering is offered to sophomores, juniors, and seniors. We developed this course at the national level through a grant from the National Science Foundation, its origin based on the need for pre-college survey courses that stimulate interest in careers in engineering and technology. This course explores the relationship between math, science and technology. Students must know and learn to communicate these relationships if America is to remain competitive in the world markets.

In teaching the Principles of Engineering course for the past four years, I have found that learning to navigate the road to the solution is just as important, if not more important as finding the solution itself. We need to teach the learning process that students require in order to navigate that road. Although all students will not become engineers, they do need problem solving skills for life in the technologically complex $21^{\text {st }}$ Century. Students complete fourteen to eighteen different case studies in a one-year class of engineering. During this journey, all students are required to complete daily logs (lab reports) to document this process, just as any engineer or scientist would do.

The course is organized around a set of concepts, skills and attitudes necessary for an engineering career. Unfortunately, students in many other schools can still graduate having had no practical contact with engineering concepts or case studies. A major problem of secondary education is that schools teach science, technology, and mathematics only in the context of the specific disciplines. This course solves that problem. It shows students the important engineering concepts and has them work on real-world case studies resembling the problems they will be solving in an engineering career. Examples of some these exciting case studies can be found on the programs website: www.imagine101.com

To begin the course, after teaching them the general concepts of engineering, I try to infuse in them the excitement that comes from learning how everything we do and touch is somehow 
connected to engineering. Although most students want to be in this elective course, we still have to bait the hook. They learn quickly that this will not be like any other course they have had. Too many traditional classrooms have students sitting in rows, discouraging their talking with each other. Yet we expect them to communicate and interact with people all day long when working. This course encourages communication with each other while sharing ideas. To avoid the "boring" reaction students have to science and math courses, I teach students to think like engineers, bringing forward the ideas of creativity, and illogical thinking. Many times we teach students what they can't do instead of fostering ideas that may have a chance. For example: if we give a fourth grade student and a veteran engineer the same problem to solve, who will generate the more creative ideas? More often than not the child, who has not been taught the limitations of materials or production techniques, will submit the more creative ideas. Students have to be taught how to solve genuine problems, not to emulate the teacher.

After I give the students a problem to solve, the methods they choose to attack the problem are their call. They use the instruction they receive from me as well as what they have learned from other courses. Given a problem and time to solve it, some students may produce a solution using the space of an entire room, some only a small portion of a tabletop. Of course, if they don't meet the parameters I might have put on the case study, their evaluation will be effected.

We should let them learn by asking, "What happens if?" or, "Could we try this?" Students' must be able to bring their innovative ideas into the light.

\section{Details of engineering instruction}

In the Engineering course at Madison West High School, all students start on a simple case study introducing them to brainstorming and thumbnail sketching, problem solving techniques that they may or may not know. In Engineering 1 they are taught that good brainstorming means getting everything down on paper in thumbnail sketches, drawings that try to capture the thinking. They learn that ideas not expressed in a communicable medium will exist in the designers' minds alone. I demand that they sit and focus on generating ideas for 20 minutes at a time, no more. I tell the students that probably $75 \%$ of their ideas are going to be sub-par, but that's normal. So, only one out of four ideas will be developed into a final solution.

During the final development toward the solution, students are instructed to pay close attention to the designs that they thought would never work; they learn that pieces of these designs may become parts of their final design. After developing several possible final solutions on paper, they must pick one to build and test as a prototype.

The case study we run first calls for a prototype that we can test only once because it will be destroyed or the structural integrity will be compromised enough so that the prototype is rendered useless. They will run the prototype through several tests that will tell them whether or not the design will work or is flawed. When a prototype fails, a designer has to go back to the "drawing boards," the $75 \%$ of the "sub par" ideas generated during the thumbnail sketch time. They look at 
all of the ideas that they originally sketched to try to develop a new design for the solution to the problem. This method may involve taking many different parts and systems out of all of the thumbnail sketches and grouping them together to produce a design. Every subsequent design that they develop should be tested just as thoroughly as, if not more, the first prototype.

Engineers and engineering students must have certain core abilities to succeed. When developing solutions, good students will learn these seven core areas. Without them, students may just be doing projects without having the entire engineering experience. The eight core areas are: systems, engineering design, modeling, problem solving, optimization, technology-society interaction, concurrent engineering and ethics. These areas represent vital parts of instruction to any engineering student. The following is a description of each section and several examples that are used in lectures within the course.

A SYSTEM is a means of achieving a desired result. It has input, process, output and feedback. The system approach can also be considered a way of thinking. Whenever you are posed with a problem or a case study, simply break it down into smaller sub-systems to simplify the approach. For example, an automobile has systems and sub-systems: Mechanical systems (gears and pulleys); electrical systems (battery, wiring and now computers in new cars); and fluid systems. As the driver, you become the input part of the system when you feed the car information in the form of pressure on gas and brake pedals. You manipulate a wheel mounted to a column that controls direction of the vehicle. (For those wanting adventure, you slip into four-wheel drive and take your $\$ 35,000$ sport utility vehicle off-roading into the woods to "get your money's worth.”)

The automobile converts the input to process, obeying the driver's signals and converting it into output. Does the vehicle "want" to engage its four-wheel drive? Will the brakes "choose" to function correctly when the driver "miscalculates" and has to slam on them only ten feet from a tree or another vehicle?

If one of these systems fails, the driver certainly wants to have feedback. In a vehicle, the gauges and displays give one form of feedback-- from the fuel gauge to the large "idiot" lights that tell you simply that something is wrong with your engine. We do not think of these "feedbacks" consciously until a crisis arises, like looking down at your speedometer after passing a policeman and saying, "Boy, I sure am glad my feedback gauge is working correctly."

ENGINEERING DESIGN is the process used by engineers to generate products, processes and systems based on the recognition of a need. The following are significant factors in the design process that students should use in all case studies.

Functionality - the product or solution must fulfill its intended purpose. In teaching functionality I use a table. After jumping on top of a small table students use for studying, I begin my story on functionality. Mildly creating a stir, I say to students, "If the table I am now standing on, were to collapse under my weight I would surely fall on my face and ruin the outstanding relationship I 
have with the student body and the community I live in." I ask them: "Was this table intended to support my weight?" Staring and sometimes laughing, the students agree that it was not.

Quality - the product or solution must be designed to meet certain minimum standards. We begin the discussion on quality by talking about the soles of our shoes. I ask the students how long they think their shoes will last. Most say that they use them for no more than two years. So then why, if most of our day is spent walking or running on harder surfaces, such as concrete, are our shoes bottomed with a softer surface like rubber? Of course we all know the answer, comfort. I tell them the story of the first pair of shoes I bought to teach in. These were very stylish expensive shoes with a sole advertised to last longer than the average sole, and, of course, knowing that I was going to be teaching for a while, I bought those shoes. This big mistake became apparent after only a few days: I was constantly tired, my back always hurt. I had spent what I had in my bank account on those "cool" shoes, and, being 1,200 miles from home in the Dallas/Fort Worth Metroplex, I could not run to my closet to pick out a different pair. We then discuss quality in relationship to the conditions of the item's intended use. This spin-off of functionality is important because quality is defined according to the proper or improper use of use of the item. I ask the students if their casual shoes were intended to be used to play basketball in, and if so, would they have quality issues when they used them in the incorrect environment. They all agree that quality has to be evaluated in the context.

Safety - the product must be designed to comply with codes and regulations to provide safe use and operation by the user. Americans are becoming more safety conscious than ever, in everything from our cars to our homes. Air bags have become the norm in passenger vehicles since 1997; however, some have posed deadly problems. The force to which they are activated in an accident has injured many people, some of them fatally. These early air bags intended to save lives sometimes activated not as the result of an accident. Sometimes the driver's installation of a child car seat incorrectly, (facing the windshield) injured and killed many small children from the inflating force of the air bag. Sometimes a driver on a crowded city street heard, "BANG," then faced a huge off white pillow shooting in his face, blocking his vision. These first generation airbags have been redesigned. Now a switch exists to turn off the passenger seat air bag for several different reasons ranging from a person who is taller to those that are very short. The driver now has the option to disable the air bag.

Ergonomics - the product must be designed so that the user can operate it with ease and maximum efficiency. Ergonomics is also called human factors engineering. Designing chairs for genuine long-term or short-term comfort is a part of ergonomics. One famous fast food chain restaurant designs the chairs so that customers are comfortable only for the time it takes to eat the kind of food served. Then the customer will leave so employees can clean the table and chair for the next person. A restaurant packed full of "lay-z-boys" and big screen TV's will keep customers there for at least a few hours at a time. I love to tell students this story about a friend of mine. He and his wife, traveling out east with their three children in their new conversion van, had agreed that, with all their traveling and the long distances involved, they needed a large vehicle to cart 
around the family. After they bought the van, he began the drive, until fatigue set in, and he turned the wheel over to his wife and got some sleep. When he awoke from his nap, he noticed that they weren't near the planned city they were supposed to be; she was driving at only $45 \mathrm{MPH}$ on the expressway. When he asked her why she was going so slow, she replied that it was as fast as she could go: her feet could not press any further down on the pedals. The manufacturer had never considered that an adult only 4'11" in height would drive this full sized conversion van. Needless to say, he did most of the remainder of driving, and they didn't own the van much longer.

Appearance - the appeal of a product is based on the selection of materials, processes, finish, color or shape. If you as a potential consumer don't like what a finished product looks like, you are less likely to purchase it. For example, recently I was shopping in a mall in town. A friend and I were looking for a new baseball hat that would not stick up in the front near the forehead and one that had a bill that could be conformed to our liking. Of course, we did find one particular hat that met our appearance standards. But we also found some rather interesting hats being sold at the store. Our idea of a "new" hat was one that was colorful and clean, with no rips or tears. This particular store sold hats that had torn, pre-formed, and dirty bills. I suppose this style emulated the fashion of stonewashed jeans and preshrunk fabrics; however, these pre-worn hats held no appeal for me, therefore, no purchase.

Environmental Considerations - the product must be designed so that it does not adversely affect the environment. In saying this, many people immediately think of oil dripping from their cars and smog over a city. While both of these adverse conditions are included in this category, there are also many others. Wind tunnels serve as an example. I spent three years in Architectural School at a university that hardly considered studying the effects wind on any proposed building to be constructed. As a result a five-mile an hour breeze on certain areas of the campus could sometimes be increased by the configuration and heights of the buildings into a 15-mile an hour wind.

Economics - the product must be produced at the least cost without sacrificing safety. Engineers are poised to keep costs down to increase company profit. Often they take cuts in production, short cuts that lead to unsafe products. More often than not, we as the public are not concerned, nor do we know about these actions taken by companies until something drastic happens. Usually it takes a death or a disaster to focus our attention. For example, consider the Sam Poong department store in Japan that collapsed, killing 1,500 people. Store management left the building early in the morning after cracks appeared in the walls and ceiling, but they did not tell employees or customers of the danger. Roaming and shopping throughout the building went on as usual. Then the fifth floor collapsed onto the fourth, setting off a chain reaction all the way to the ground level. The building collapsed because of poor building codes and their enforcement paired with the fact that the firm doing the concrete work added entirely too much water to the concrete mix to lessen the costs, creating a very weak concrete structure. 
MODELING is a method of illustrating a solution to a practical problem. Students need to understand that engineers and technicians can use different forms of modeling to assess and develop a product. The types of modeling are descriptive, functional, mathematical and scale. Descriptive modeling may include diagrams, graphs, flow charts and block diagrams. Verbal modeling describes the behavior of systems. Mathematical modeling in the form of equations shows the relationship between variables in the systems. Scale models may also be included in descriptive modeling.

Functional modeling may include computer simulations that support investigations of system behaviors or physical models of real systems with moving parts.

Examples of descriptive modeling from a project might include: a 3-dimensional CAD drawing of a structure to be constructed, a verbal description of the materials to be used, heat flow formulas, and scale models of the actual systems.

PROBLEM SOLVING. When faced with a problem to be resolved, engineers and technicians must proceed through a series of problem solving steps. They include:

1. Recognition of need - products created are a direct response to specific needs and wants of society.

2. Definition of the problem - all of the specifications that affect the design of the product must be clearly stated.

3. Analysis of the problem - brainstorming must take place to formulate possible solutions.

4. Selection of a solution - an optimal solution must be chosen with the aid of a modeling system.

5. Implementation or realization - components required for the construction are obtained to complete the construction of a prototype.

6. Evaluations and testing - analysis of the prototype to determine if the specifications are met.

7. Re-design - modifications to the prototype based on the evaluation and testing phase.

OPTIMIZATION Most design problems we face have no definitive answer. Most solutions are a series of compromises, which in turn allow the product to function well. An engineer or technician must assess all the parts of a problem and optimize each before the job is resolved.

TECHNOLOGY-SOCIETY INTERACTION When developing a new technology, engineers and technicians must consider the impact of that technology on society. When considering the new technology, two types of decisions must be made. A cost benefit analysis, does the cost justify the product? A risk benefit analysis, does the risk of building the product outweigh the negative societal impact?

Proceedings of the 2001 American Society for Engineering Education Annual Conference \& Exposition Copyright (O) 2001, American Society for Engineering Education 
CONCURRENT ENGINEERING When a project is initiated, a team of professionals is called together to do the planning. The team may include various types of engineers, technicians, draftspersons, etc. A project engineer may coordinate all aspects of the project. This process is concurrent engineering. One of the simplest ways of teaching concurrent engineering is to divide students in two equal groups and separate them physically (put one group in the hallway or another room). Each individual in group one (pick either) receives one sheet of $8 \frac{1}{2}$ " $x 11$ " copy paper and is told to make a box. The second group (preferably one the instructor is in direct supervision of) of people are given the exact piece of paper and told to make a paper airplane; test flights are not an option in this exercise. After five minutes pass, ask the groups to come together and pair up with someone in the opposite group. Now their instruction is to put the airplane in the box. The questions are asked to the group: would you have deigned the box differently if you knew a paper airplane would have to fit into it? would you have designed the paper airplane differently if you know it had to fit into a paper box?

An ETHICS statement from the Engineers Council for Professional Development says, "Engineers shall hold paramount the safety, health, and welfare of the public in the performance of their professional duties." Engineers and technicians must uphold and advance the integrity, honor and dignity of the engineering profession. Students in these courses are faced with cases from NSPE that have come before the board and discuss the issues. Students also are required to write an essay that addresses specific ethical issues in an actual case study, such as the space shuttle challenger accident, citing the code of ethics where necessary.

\section{Materials science in the classroom}

Materials make modern life possible, from the polymers in the chair you sit on and the metal ballpoint pen you write with, to the concrete that is used for all roads and buildings. All these items are products of Materials Science and Technology. Materials Science involves designing, choosing, testing and using materials such as metals, polymers, ceramics and composites. Making glass from sand, designing and casting metals, analysis of metals, as well as developing and destructive testing of concrete are a few of the 66 different experiments in this class. Students interested in careers in Science, Engineering, Art and Technology will benefit from the knowledge gained in Materials Science ${ }^{2}$.

This introductory course combines the academic disciplines of chemistry, physics and engineering to create a materials science and technology curriculum. The course covers the fundamentals of ceramics, glass, metals, polymers and composites. Designed to appeal to a broad range of students, the course combines hands-on activities, demonstrations and long-term student project descriptions. The basic philosophy of the course is for students to observe, experiment, record, question, seek additional information and, through creative and insightful thinking, solve problems 
related to materials science and technology ${ }^{3}$.

\section{Details of Materials Science Instruction}

Students in the materials science class have many different topics and experiments to go through in the one-year class. Historical developments and manufacturing processes are major parts of each unit. The Pacific Northwest Laboratory in Richland, WA and Batelle Institute developed this curriculum initially in the late 1980's under support from the U.S. Department of Energy. Areas discussed include metals, ceramics, polymers and composites.

In the metals unit, students explore the many properties and historical developments of metals. Students investigate the mechanical properties of metals along with the effects of heat-treating. They also discuss different types of alloys and alloying techniques as well as the study of binary phase diagrams.

In the ceramics unit, students learn that most ceramics are crystalline solids that have properties related to the covalent or ionic bonds that hold them together. They also learn that metal oxides are used to color glass, and they make glass from basic chemical ingredients.

Students learn about synthetic polymers and the chemistry involved with them in the polymers unit. The course covers how polymers can be categorized in many ways, and that they are frequently altered chemically or with additives. They receive information on recycling and the techniques used along with the chemical changes brought about by cross-linking.

The composites unit helps bring together information that has been presented and materials that have been experimented with throughout the course. It is also the most exciting and relevant to the students. Most higher end recreational equipment is made with some type of composite; therefore, they have a direct link to this unit. Students study strength to weight ratios, including strength measuring, testing, and altering. Wood and concrete are two traditional composites students are familiar with and are used to introduce many concepts. Uni-directional and bi-directional carbon fiber, Kevlar and plain weave fiberglass reinforced composites are a few of the materials that students experiment with. They examine hand lay-ups, vacuum bagging and pre-preg materials and their manufacturing processes.

The ceramics unit includes an experiment created in partnership with the University of Wisconsin's College of Engineering. The following is an overview of the superconductivity experiment used in class.

In the zero resistance experiment, students measure the loss of resistance in a superconductor by monitoring the voltage due to a constant current passing through the superconductor as it is cooled in a liquid nitrogen bath. For comparison, students will also measure the resistance of a pure metal foil, which will not drop to zero but will decrease upon cooling. The superconductor in this experiment is a tape composed of a $\mathrm{Bi}_{2} \mathrm{Sr}_{2} \mathrm{Ca}_{2} \mathrm{Cu}_{3} \mathrm{O}_{14}$ ceramic core and a silver sheath. The 
bismuth oxide ceramic is the superconducting material, which loses resistance at about $110 \mathrm{~K}$, well above the temperature of a liquid nitrogen bath, $77 \mathrm{~K}$. This experiment was created in partnership with the University of Wisconsin's College of Engineering.

\section{The future of K-12 Education}

If everything we do is the same as we have done in the past and no evolution of programs takes place, our students will either find different venues to practice in or our programs will vanish, such as the school board's decision to eliminate several classes in New Berlin, WI. Engineering, combined with Materials Science is what I believe to be the answer to what education will look like for the next 100 years. These programs must also recognize that other instructors in the math, science, and English departments play significant roles in an engineering program. Students work hard during their entire school day in other classes. The engineering program takes what they learn with other teachers along with information teachers in our department provide and applies it to solve problems. Suddenly, education looks more like it should, a cooperative effort to supply our students with the best experiences possible, utilizing every resource possible, including other teachers. This dream of an engineering program in every school district in the nation can become a reality. Visit the programs website at: www.imagine101.com

\section{Bibliography}

1. International Technology Education Association, The Technology Teacher VOL 59 NO. 6 Pg 17-22. Engineering, but how? Alan G. Gomez (March, 2000)

2 URL: http://www.madison.k12.wi.us/west/course/technology.htm; Course information and descriptions for Madison West High School, Madison, WI.

3. URL: http://www.pnl.gov/education/mst.htm; Original course development site. This site also contains the FREE original curriculum for classroom instruction for download in .PDF format. U.S. Department of Energy National Teacher Institute In Materials Science \& Technology (Pacific Northwest Laboratory).

\section{ALAN G. GOMEZ}

Alan Gregory Gomez is currently an Engineering and Technology Teacher Madison West High School in Madison, Wisconsin. He also teaches one of the freshman engineering courses at the University of Wisconsin-Madison. He received his B.S. in Technology Education from the University of Wisconsin-Stout in 1995 and continues work on his M.S. in education. He has taught in several locations including Fort Worth, TX, Minneapolis, MN and Madison, WI. Alan frequently holds state and national workshops to encourage and inform instructors and administrators about the benefits and necessity of engineering education in their school districts. Alan was a member of the technology education standards writing team for the state of Wisconsin and is currently writing a national Foundations of Technology curriculum for ITEA's Center to Advance the Teaching of Technology \& Science. 